\title{
Correlation of Topometric and Tomographic Indices with Visual Acuity in Patients with Keratoconus
}

\author{
Bernardo T Lopes, Isaac C Ramos, Fernando Faria-Correia, Allan Luz, Bruno de Freitas Valbon, \\ Michael Wellington Belin, Renato Ambrósio Jr
}

\begin{abstract}
Purpose: To evaluate the correlations of Pentacam keratometric, topometric (derived from front surface curvature) and tomographic (derived from 3D corneal shape analysis) indices with best corrected visual acuity in patients with keratoconus.
\end{abstract}

Materials and methods: One eye randomly selected of 123 patients with bilateral keratoconus was retrospectively enrolled. All patients underwent a comprehensive ophthalmic examination including subjective refraction, distance best-spectacle corrected visual acuity (DCVA) measurement, and rotating Scheimpflug corneal tomography (Pentacam HR; O culus, Wetzlar, Germany) at the same office visit. The correlations between the logarithm of the minimum angle of resolution (LogMAR) of DCVA and keratometric indices, topometric indices and tomographic indices were tested with nonparametric Spearman correlation coefficients $(\rho)$.

Results: The mean LogMAR DCVA was $0.32(\sim 20 / 42) \pm 0.27$ [range: $-0.10(20 / 15)$ to $1.30(20 / 400)]$. There were strong correlations between DCVA and many keratometric, topometric and tomographic indices. A strong positive correlation was found between DCVA and BAD-Df $(\rho=0.648, p<0.001), B A D-D b$ $(\rho=0.633, p<0.001), K 2(\rho=0.643, p<0.001), K_{\max }(\rho=0.608$, $p<0.001)$, TKC $(\rho=0.558, p<0.001), B A D-D(\rho=0.577, p<$ $0.001)$, ISV $(\rho=0.573, p<0.001)$, CKI $(\rho=0.530, p<0.001)$, $\mathrm{KI}(\rho=0.531, p<0.001)$. A strong negative correlation was seen between DCVA and Asph Q front $30^{\circ}(\rho=-0.521$, $\mathrm{p}<0.001)$

Conclusion: There are significant correlations between visual acuity and Pentacam parameters. Such parameters may be considered for improving staging of the disease, as well as for monitoring progression or treatment as outcome measures. There is a potential for combining parameters to enhance the correlations.

Keywords: Keratoconus, Corneal tomography, Visual acuity, Pentacam.

How to cite this article: Lopes BT, Ramos IC, Faria-Correia F, Luz A, de Freitas Valbon B, Belin MW, Ambrósio R J r. Correlation of Topometric and Tomographic Indices with Visual Acuity in Patients with Keratoconus. Int J Kerat Ect Cor Dis 2012;1(3):167-172.

\section{Source of support: Nil}

Conflict of interest: None declared

\section{INTRODUCTION}

Keratoconus is a bilateral, asymmetric, progressive, noninammatory corneal ectatic disease characterized by central thinning and anterior protrusion of the cornea. ${ }^{1,2}$ These changes may result in irregular astigmatism, progressive myopia and increase in higher order aberrations leading to visual impairment. ${ }^{3,4}$ Since the invention of the keratoscope in the 19th century, technology has evolved to improve the capability to detect both the visual effects and physical findings of keratoconus. ${ }^{5,6}$ Reynolds and $\mathrm{K}$ ratt in 1959 were the first to incorporate computer analysis to the Placido image. This work was later advanced by K lyce in the 1980s who first produced color-coded maps of the front surface of the cornea. ${ }^{7-11}$ Further, hardware development included optical cross-sectional analysis which allowed for imaging of both the anterior and posterior corneal surfaces and thus additionally a full pachymetric map. ${ }^{12-17}$ The Pentacam ( 0 culus Optikgeräte $\mathrm{G}$ mbH , W etzlar, Germany) is a cornea and anterior segment tomography (CASTm) device, based on a rotating Scheimpflug camera with good precision (repeatability and reproducibility). ${ }^{18}$ The additional information permits a better understanding of the optical aberrations caused by keratoconus and its effects on the quality of vision. ${ }^{4,19-22}$

In this study we examined the correlations of Pentacam's keratometric, topometric and tomographic indices with distance corrected visual acuity (DCVA) in patients with known keratoconus.

\section{MATERIALS AND METHODS}

One eye randomly selected of 123 patients with bilateral keratoconus was retrospectively enrolled. All patients underwent a comprehensive ophthalmic examination including subjective refraction, best corrected visual acuity (DCV A) measurement, slit-lamp biomicroscopy for seeking corneal signs of keratoconus (such as V ogt's striae, Fleischer ring, abnormal corneal thinning). Patients with extensive corneal scarring and previous corneal surgery were excluded. Along with ocular examination, all eyes were examined by Placido-disk-based corneal topography (K eratograph Topography System; Oculus, W etzlar, Germany) and rotating Scheimpflug corneal tomography (Pentacam HR; O culus, Wetzlar, Germany) at the same office visit. The Pentacam software was used to automatically extract the data from each examination into a Microsoft Excel (Microsoft, Redmond, Washington) spreadsheet.

Diagnosis of keratoconus was based on Placido-diskbased axial topography, elevation-derived anterior corneal 
curvature maps, ${ }^{2}$ and criteria used in the collaborative longitudinal evaluation of keratoconus (CLEK) study. ${ }^{23}$

The keratometric indices of curvature on the flattest meridian (K 1 ), on the steepest meridian (K 2 ) and total amount of corneal astigmatism (A st) were analyzed. The following front surface derived indices were analyzed: Steepest keratometry $\left(\mathrm{K}_{\max }\right)$; index of surface variance (ISV), a general measure of corneal surface irregularity; index of vertical asymmetry (IVA), a measure of the difference between superior curvature and inferior curvature in the cornea (IS-V alue) (similar to the commonly used I-S ratio): ${ }^{24,25}$ keratoconus index (KI); central keratoconus index $(\mathrm{CKI})$; index of height asymmetry (IHA), the degree of symmetry of height data with respect to the horizontal meridian as axis of reflection; and index of height decentration (IHD), calculated with Fourier analysis of corneal height to quantify the degree of decentration in vertical direction. The oculus topographic keratoconus classification (TKC) ${ }^{26}$ and front surface aspherecity at $30^{\circ}$ (A sph Q front $30^{\circ}$ ) were assessed.

The elevation parameters derived from the front and back surfaces at the apex, at the thinnest point and the point with highest value within the $4 \mathrm{~mm}$ (diameter) zone centered at the apex were calculated using the $8 \mathrm{~mm}$ best-fit sphere (BFS) and $8 \mathrm{~mm}$ best-fit toric ellipsoid (BFTE) references were computed. Back surface asphericity at $30^{\circ}$ (A sph Q back $30^{\circ}$ ). Corneal thickness at the apex (Pachy apex) and at the thinnest point (Pachy min); pachymetric progression index at the meridian with minimum pachymetric increase (PPI min), maximal (PPI max) and the average of all meridians (PPI ave); and the relational thickness to these parameters (ART min, ART max and ART ave) were registered. ${ }^{27}$ The B elin/A mbrósio enhanced ectasia display (BAD) deviation indices were computed, along with the $B A D-D$ value which combines these indices based on a linear regression analysis.

Statistical analysis was accomplished using B ioE stat 5.0 (Instituto M amirauá, A mazonas, B razil) and M edC alc 11.1 ( $M$ edCalc Software, M ariakerke, B elgium). KolmogorovSmirnov goodness of fit test was used to assess the normality of the distribution of the parameters. As the DCV A, noted as the logarithm of the minimum angle of resolution ( $\log M A R)$, has not shown a normal distribution, nonparametric Spearman correlation coefficients $(\rho)$ were calculated. A $p$-value $<0.05$ was considered statistically significant.

\section{RESULTS}

A total of 123 eyes randomly selected of 123 patients were included. There were 70 men and 53 women, 63 right eyes and 60 left eyes. The mean age of the patients was $30.68 \pm$
9.86 years (range: 14 to 59 years) and their mean L ogM A R DCV A was $0.32 \pm 0.27$ (range: -0.08 to 1.30 ). A ccording to the Krumeich-A msler classication of the severity of keratoconus, ${ }^{28} 14$ (11.4\%) eyes were classied as grade I, 46 (37.4\%) eyes as grade II, 49 (39.8\%) eyes as grade III, and two (1.6\%) eyes as grade IV. The O culus TK C system (based on anterior surface indices) identified $90.2 \%$ of patients as keratoconic.

Table 1 shows the correlation coefficients between DCVA and parameters derived from the front surface and TK C. There were strong positive correlation between DCVA and K $2(\rho=0.643, p<0.001), K_{\max }(\rho=0.608, p<0.001)$, ISV $(\rho=0.573, p<0.001), C K I(\rho=0.530, p<0.001), K$ I $(\rho=0.531, p<0.001)$ and TKC $(\rho=0.558, p<0.001)$. Front surface asphericity at $30^{\circ}$ (A sph $Q$ front $\left.30^{\circ}\right)$ had shown a strong negative correlation with DCVA $(\rho=$ $-0.521, p<0.001)$. There was no correlation between IHA and DCVA .

The correlation coefficients between tomographic parameters (derived from 3D corneal shape) and DCVA are shown in Table 2. A strong correlation could be seen between DCVA and BAD-Df $(\rho=0.648, p<0.001), B A D$ $\mathrm{Db}(\rho=0.633, p<0.001)$ and BAD-D $(\rho=0.577, p<$ 0.001 ). The most correlated elevation indices using $8 \mathrm{~mm}$ BFS with DCVA were front $(\rho=0.570, p<0.001)$ and back el evation $(\rho=0.591, p<0.001)$ at the apex. U sing the $8 \mathrm{~mm} \mathrm{BFTE}$ the anterior elevation at the thinnest point had shown the strongest correlation $\rho=0.570, p<0.001)$. PPI $\min (\rho=0.498, p<0.001)$ and ART $\min (\rho=-0.498, p<$ 0.001 ) had a moderate positive and negative correlation with DCV A respectively. Back surface asphericity $(\rho=-0.508$,

Table 1: Correlation coefficients between front surface-derived parameters and visual acuity in patients with keratoconus

\begin{tabular}{lcr}
\hline & $\rho$ & $p$-value \\
\hline K1 & 0.499 & $<0.001$ \\
K2 & 0.643 & $<0.001$ \\
Astig & 0.423 & $<0.001$ \\
K $_{\max }$ & 0.608 & $<0.001$ \\
ISV & 0.573 & $<0.001$ \\
IVA & 0.445 & $<0.001$ \\
IS value & 0.421 & $<0.001$ \\
KI & 0.531 & $<0.001$ \\
CKI & 0.530 & $<0.001$ \\
IHA & 0.12 & 0.185 \\
IHD & 0.463 & $<0.001$ \\
TKC & 0.558 & $<0.001$ \\
Asph Q front 30 & -0.521 & $<0.001$ \\
\hline
\end{tabular}

K1: Flat meridian curvature; K2: Steepest meridian curvature; Ast: Corneal astigmatism; $K_{\text {max }}$ : Steepest front surface kera tometry; ISV: Index of surface variance; IVA: Index of vertical asymmetry; IS value: Difference between superior-inferior curvature of the cornea; $\mathrm{KI}$ : Keratoconus index; CKI: Central keratoconus index; IHA: Index of height asymmetry; IHD: Index of height decentration; TKC: Oculus topographic keratoconus classification; Asph Q front $30^{\circ}$ : Front surface asphericity at $30^{\circ}$ 
Table 2: Correlation coefficients between tomographic parameters and visual acuity in patients with keratoconus

\begin{tabular}{|c|c|c|}
\hline & $\rho$ & $p$-value \\
\hline BAD-Df & 0.648 & $<0.001$ \\
\hline BAD-Db & 0.633 & $<0.001$ \\
\hline BAD-D & 0.577 & $<0.001$ \\
\hline Ele F BFS $8 \mathrm{~mm}$ apex & 0.570 & $<0.001$ \\
\hline Ele F BFS $8 \mathrm{~mm}$ thinnest & 0.543 & $<0.001$ \\
\hline Ele F BFS $8 \mathrm{~mm} \max .4 \mathrm{~mm}$ zone & 0.506 & $<0.001$ \\
\hline Ele B BFS 8 mm apex & 0.591 & $<0.001$ \\
\hline Ele B BFS $8 \mathrm{~mm}$ thinnest & 0.536 & $<0.001$ \\
\hline Ele B BFS $8 \mathrm{~mm}$ max. $4 \mathrm{~mm}$ zone & 0.510 & $<0.001$ \\
\hline Ele F BFTE $8 \mathrm{~mm}$ apex & 0.518 & $<0.001$ \\
\hline Ele F BFTE $8 \mathrm{~mm}$ thinnest & 0.570 & $<0.001$ \\
\hline Ele F BFTE $8 \mathrm{~mm}$ max. $4 \mathrm{~mm}$ zone & 0.529 & $<0.001$ \\
\hline Ele B BFTE $8 \mathrm{~mm}$ apex & 0.527 & $<0.001$ \\
\hline Ele B BFTE $8 \mathrm{~mm}$ thinnest & 0.532 & $<0.001$ \\
\hline Ele B BFTE $8 \mathrm{~mm} \max .4 \mathrm{~mm}$ zone & 0.507 & $<0.001$ \\
\hline PPI min & 0.498 & $<0.001$ \\
\hline PPI max & 0.375 & $<0.001$ \\
\hline PPI avg & 0.469 & $<0.001$ \\
\hline ART min & -0.498 & $<0.001$ \\
\hline ART max & -0.370 & $<0.001$ \\
\hline ART avg & -0.453 & $<0.001$ \\
\hline Pachy min & -0.316 & $<0.001$ \\
\hline Pachy apex & -0.324 & $<0.001$ \\
\hline Asph Q back $30^{\circ}$ & -0.508 & $<0.001$ \\
\hline
\end{tabular}

BAD-Df: Deviation of front elevation difference map; BAD-Db: Deviation of front elevation difference map; BAD-D: Belin/Ambrósio enhanced ectasia total deviation value; Ele F BFS $8 \mathrm{~mm}$ apex: F ront surface elevation at the apex using the $8 \mathrm{~mm}$ best-fit sphere; Ele F BFS $8 \mathrm{~mm}$ thinnest: Front surface elevation at the thinnest point using the $8 \mathrm{~mm}$ best-fit sphere; Ele F BFS $8 \mathrm{~mm} \max 4 \mathrm{~mm}$ zone: F ront surface elevation at the point with highest value within the $4 \mathrm{~mm}$ (diameter) zone centered at the apex using the $8 \mathrm{~mm}$ best-fit sphere; Ele B BFS $8 \mathrm{~mm}$ apex: Back surface elevation at the apex using the $8 \mathrm{~mm}$ best-fit sphere; Ele B BFS $8 \mathrm{~mm}$ thinnest: Back surface elevation at the thinnest point using the $8 \mathrm{~mm}$ best-fit sphere, Ele B BFS $8 \mathrm{~mm}$ max $4 \mathrm{~mm}$ zone: Back surface elevation at the point with highest value within the $4 \mathrm{~mm}$ (diameter) zone centered at the apex using the $8 \mathrm{~mm}$ best-fit sphere; Ele F BFTE $8 \mathrm{~mm}$ apex: Front surface elevation at the apex using the $8 \mathrm{~mm}$ best-fit toric ellipsoid; Ele F BFTE $8 \mathrm{~mm}$ thinnest: Front surface elevation at the thinnest point using the $8 \mathrm{~mm}$ best-fit toric ellipsoid; Ele F BFTE $8 \mathrm{~mm} \max 4 \mathrm{~mm}$ zone: Front surface elevation at the point with highest value within the $4 \mathrm{~mm}$ (diameter) zone centered at the apex using the $8 \mathrm{~mm}$ best-fit toric ellipsoid; Ele B BFTE $8 \mathrm{~mm}$ apex: Back surface elevation at the apex using the $8 \mathrm{~mm}$ best-fit toric ellipsoid; Ele B BFTE $8 \mathrm{~mm}$ thinnest: Back surface elevation at the thinnest point using the $8 \mathrm{~mm}$ best-fit toric ellipsoid; Ele B BFTE $8 \mathrm{~mm} \max 4 \mathrm{~mm}$ zone: Back surface elevation at the point with highest value within the $4 \mathrm{~mm}$ (diameter) zone centered at the apex using the $8 \mathrm{~mm}$ best-fit toric ellipsoid; PPI min: Minimum pachymetric progression index; PPI max: Maximum pachymetric progression index; PPI ave: Average pachymetric progression index; AR T min: Ambrósio relational thickness minimum; ART max: Ambrósio relational thickness maximum; ART ave: Ambrósio relational thickness average; $P$ achy apex: Corneal thickness at the apex; Pachy min: Corneal thickness at the thinnest point; Asph Q back 30 : : Back surface asphericity at $30^{\circ}$

$p<0.001)$ also had shown a moderate negative correlation with DCV A. Pachy apex $(\rho=-0.324, p<0.001)$ had a mild negative correlation with DCVA. Figure 1 illustrates the best correlation coefficients between topometrics and tomographics parameters and DCVA.

\section{DISCUSSION}

Corneal tomography has emerged as an important tool for diagnosing keratoconus. ${ }^{29} \mathrm{~N}$ ewer and varied treatment modalities, such as intracorneal rings, ${ }^{30-32}$ corneal collagen cross-linking, ${ }^{33,34}$ and excimer laser therapeutic al bations, ${ }^{35}$ have increased the need for better sensitivity and specificity in diagnosing keratoconus.

$M$ aeda et al have shown that topographic indices could well predict subtle visual deterioration in patients with keratoconus using letter contrast sensitivity. ${ }^{36}$ In our study we al so found a good correlation between keratometric and topometric indices (corneal front surface), K 2 ( $\rho=0.643$, $p<0.001), K_{\max }(\rho=0.608, p<0.001)$, ISV $(\rho=0.573$, $p<0.001)$ and $K I(\rho=0.531, p<0.001)$.

In recent years there has been an effort to aggregate information to topographic indices and clinical data in attempt to enhance keratoconus classification. The keratoconus severity score (K SS) was conceived integrating corneal aberrometry indices. ${ }^{37} \mathrm{~A}$ lió et al have developed a method to grade the disease integrating with clinical and topographic data, pachymetry, aberrometry and corneal biomechanics. They found that this method was well correlated with visual acuity of the patients. ${ }^{38} \mathrm{~A}$ limitation of all of these prior classifications were a strong reliance on anterior surface parameters. Similarly, visual degradation is most closely link to changes on the anterior corneal surface.

Newer treatment modalities, such as corneal collagen cross-linking, however, are often contemplated prior to significant visual loss and may be most appropriate at an earlier stage of disease than was typical for penetrating keratoplasty. What is unique in our study is the strong correlation with visual acuity with tomographic indices not derived from the anterior corneal surface. Corneal front and back surface elevations are well-correlated with severity of the disease $\mathrm{e}^{39}$ and thinnest corneal thickness was inversely correlated with $\mathrm{K}$ readings. ${ }^{40} \mathrm{In}$ the present study, we found a strong correlation between the deviation of front and back elevations (B elin-A mbrosio Enhanced Ectasia Display) with DCVA $\rho=0.648(p<0.001)$ and $\rho=0.633(p<0.001)$ respectively. The front and back elevations at the apex using the $8 \mathrm{~mm}$ best-fit sphere was also strong correlated with DCVA $\rho=0.570(p<0.001)$ and $\rho=0.591(p<0.001)$ respectively. Corneal pachymetry at the apex has shown a mild inverse correlation with DCVA $\rho=-0.324(p<0.001)$, but pachymetric progression index (PPI min: $\rho=0.498, p<$ 0.001 ) and A mbrosio's relational thickness (ART min: $\rho=$ $-0.498, p<0.001$ ) have demonstrated an increase in this correlation with DCVA.

Combinations of parameters using linear discriminant analysis ${ }^{41}$ or artificial intelligence ${ }^{6}$ are useful in detecting keratoconus patients. Although we found good strong 

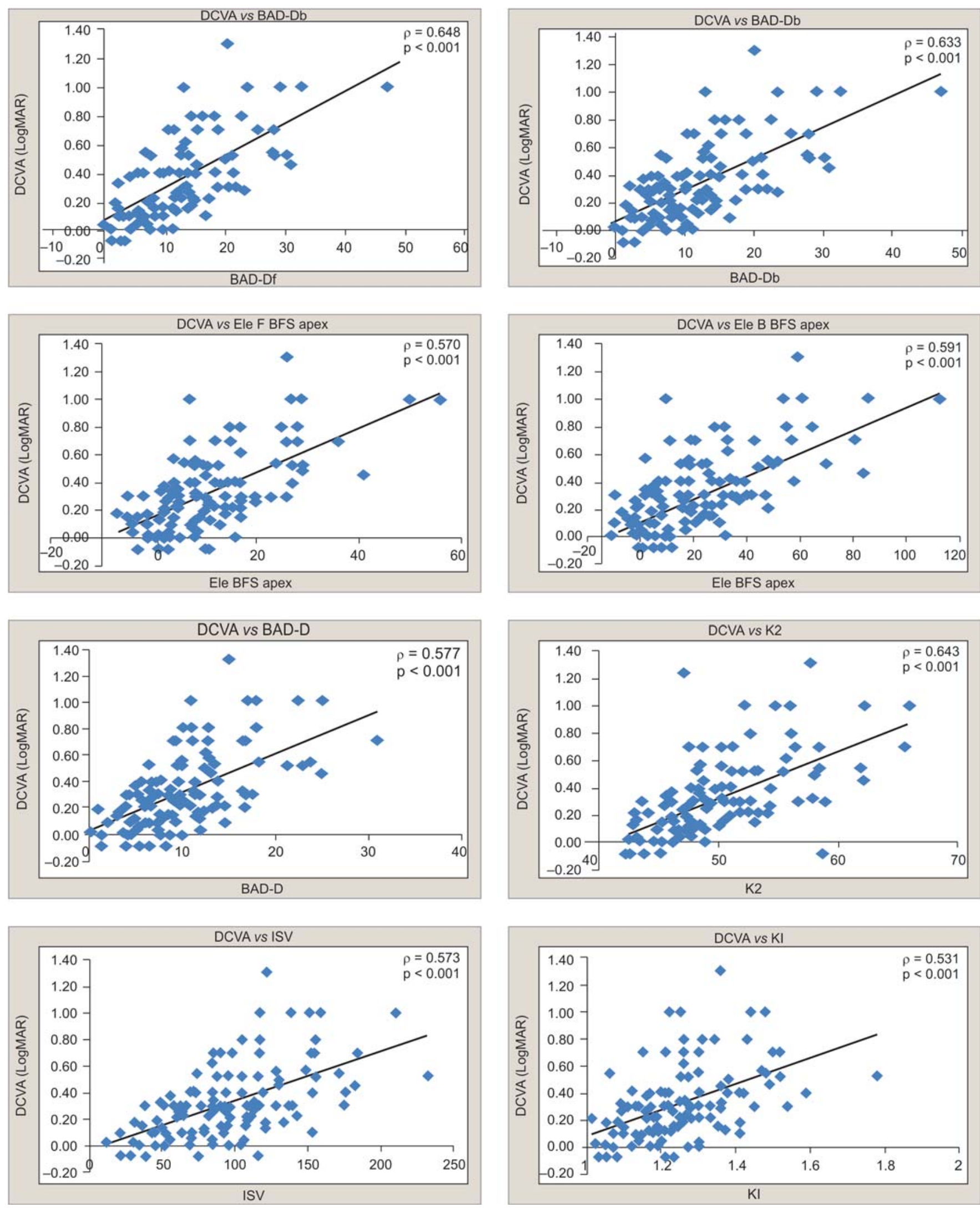

Fig. 1: Best correlations between DCVA and Pentacam's parameters (DCVA: Distance corrected visual acuity; BAD-Df: Deviation of front elevation difference map (Belin-Ambrósio enhanced ectasia display); BAD-Db: Deviation of front elevation difference map (Belin/ Ambrosio enhanced ectasia display); Ele F BFS apex: Front surface elevation at the apex using the $8 \mathrm{~mm}$ best-fit sphere; Ele B BFS apex: Back surface elevation at the apex using the $8 \mathrm{~mm}$ best-fit sphere; BAD-D: Belin/Ambrósio enhanced ectasia total deviation value; K2: Steepest meridian of the cornea; ISV: Index of surface variance; KI: Keratoconus index 
correlation indices between DCVA and tomographic parameters, combing data from tomography, topography, biomechanical properties, aberrometry and clinical can be helpful in stratifying those patients.

\section{REFERENCES}

1. K rachmer JH, Feder RS, B elin M W. Keratoconus and related noninflammatory corneal thinning disorders. Surv Ophthalmol 1984;28(4):293-322.

2. Rabinowitz Y S. K eratoconus. Surv O phthalmol 1998;42(4):297319.

3. Tuft SJ, M oodaley LC, Gregory WM, Davison CR, B uckley RJ. Prognostic factors for the progression of keratoconus. Ophthalmology 1994;101(3):439-47.

4. M aeda N, Fujikado T, K uroda T, M ihashi T, H irohara Y, N ishida $K$, et al. W avefront aberrations measured with Hartmann-Shack sensor in patients with keratoconus. Ophthalmology 2002;109(11):1996-2003.

5. Levine JR. The true inventors of the keratoscope and photokeratoscope. BrJ Hist Sci 1965;2(8):324-42.

6. A rbelaez M C, V ersaci F, V estri G, Barboni P, Savini G. U se of a support vector machine for keratoconus and subclinical keratoconus detection by topographic and tomographic data. Ophthalmology 2012;119(11):2231-38.

7. Klyce SD. Computer-assisted corneal topography. Highresolution graphic presentation and analysis of keratoscopy. Invest O phthalmol V is Sci 1984;25(12):1426-35.

8. Wilson SE, K lyce SD, Husseini ZM. Standardized color-coded maps for corneal topography. Ophthalmology 1993;100(11): 1723-27.

9. Rabinowitz Y S, M cD onnell PJ. Computer-assisted corneal topography in keratoconus. Refract Corneal Surg 1989;5(6): 400-08.

10. Wilson SE, Lin DT, Klyce SD. Corneal topography of keratoconus. Cornea 1991;10(1):2-8.

11. Wilson SE, Klyce SD. Quantitative descriptors of corneal topography. A clinical study. A rchiv Ophthalmol 1991;109(3): 349-53.

12. Huang D . A reliable corneal tomography system is still needed. Ophthalmology 2003;110(3):455-56.

13. A mbrosio R J r, B elin M W. Imaging of the cornea: Topography vs tomography. J Refract Surg 2010;26(11):847-49.

14. Belin MW, K hachikian SS, M CGhee CN, Patel D. New technology in corneal imaging. Int Ophthalmol Clin 2010;50(3):177-89.

15. Salomao M Q, Esposito A, Dupps WJ J r. A dvances in anterior segment imaging and analysis. Curr Opin Ophthalmol 2009;20(4):324-32.

16. Brautaset RL, Nilsson M, Miller WL, L each NE, Tukler JH, Bergmanson JP. Central and peripheral corneal thinning in keratoconus. Cornea 2012 M ay 3. [E pub ahead of print].

17. M ohamed S, Lee GK, Rao SK, W ong AL, Cheng A C, Li EY, et al. Repeatability and reproducibility of pachymetric mapping with $\mathrm{V}$ isante anterior segment- optical coherence tomography. Invest O phthalmol V is Sci 2007;48(12):5499-504.

18. M CA linden C, K hadka J, Pesudovs K. A comprehensive evaluation of the precision (repeatability and reproducibility) of the Oculus Pentacam HR. Invest Ophthalmol V is Sci 2011;52(10):7731-37.
19. K ymes SM , W alline JJ , Zadnik K, Gordon M O. Quality of life in keratoconus. A m J Ophthalmol 2004;138(4):527-35.

20. Kymes SM, Walline JJ, Zadnik K, Sterling J, Gordon M 0. Changes in the quality-of-life of people with keratoconus. A m J Ophthalmol 2008;145(4):611-17.

21. Cesnekova T, Skorkovska K, Petrova S, Cermakova S. V isual functions and quality of life in patients with keratoconus. Cesk Slov Oftalmol 2011;67(2):51-54.

22. M ihaltz K, K ovacs I, K ranitz K, Erdei G, N emeth J, Nagy ZZ. $M$ echanism of aberration balance and the effect on retinal image quality in keratoconus: Optical and visual characteristics of keratoconus. J Cataract R efract Surg 2011;37(5):914-22.

23. Zadnik K, Barr JT, Edrington TB, Everett DF, Jameson M, $M c M$ ahon TT, et al. Baseline findings in the collaborative longitudinal evaluation of keratoconus (CLEK) Study. Invest Ophthalmol V is Sci 1998;39(13):2537-46.

24. Rabinowitz Y S. V ideokeratographic indices to aid in screening for keratoconus. J R efract Surg 1995;11(5):371-79.

25. Li X, Y ang H, Rabinowitz Y S. Keratoconus: Classification scheme based on videokeratography and clinical signs. J Cataract Refract Surg 2009;35(9):1597-603.

26. Krumeich JH, Daniel J, K nulle A. Live-epikeratophakia for keratoconus. J Cataract R efract Surg 1998;24(4):456-63.

27. A mbrosio R J r., Caiado AL, Guerra FP, L ouzada R, Roy AS, Luz A, et al. Novel pachymetric parameters based on corneal tomography for diagnosing keratoconus. J Refract Surg 2011;27(10):753-58.

28. Krumeich JH, Kezirian GM. Circular keratotomy to reduce astigmatism and improve vision in stage I and II keratoconus. J Refract Surg 2009;25(4):357-65.

29. Correia FF, Ramos I, Lopes B, Salomão M Q, Luz A, Correa $R O$, et al. Topometric and tomographic indices for the diagnosis of keratoconus. Int J Kerat Ect Cor Dis 2012;1(2):92-99.

30. Siganos D, Ferrara P, Chatzinikolas K, B essis N, Papastergiou $G$. Ferrara intrastromal corneal rings for the correction of keratoconus. J Cataract Refract Surg 2002;28(11):1947-51.

31. Colin J, Cochener B, Savary G, M al et F. Correcting keratoconus with intracorneal rings. J Cataract Refract Surg 2000;26(8): 1117-22.

32. Torquetti L, Berbel RF, Ferrara P. Long-term follow-up of intrastromal corneal ring segments in keratoconus. J Cataract Refract Surg 2009;35(10):1768-73.

33. Wollensak G, Spoerl E, Seiler T. Riboflavin/ultraviolet-ainduced collagen crosslinking for the treatment of keratoconus. A m J Ophthalmol 2003;135(5):620-27.

34. Koller $T$, Pajic B, Vinciguerra $P$, Seiler $T$. Flattening of the cornea after collagen crosslinking for keratoconus. J Cataract Refract Surg 2011;37(8):1488-92.

35. Kanellopoulos AJ. Comparison of sequential vs same-day simultaneous collagen cross-linking and topography-guided PRK for treatment of keratoconus. J Refract Surg 2009;25(9):S812-18.

36. M aeda N, Sato S, W atanabe H, Inoue Y, Fujikado T, Shimomura $Y$, et al. Prediction of letter contrast sensitivity using videokeratographic indices. A m J Ophthalmol 2000;129(6):759-63.

37. M CM ahon TT, Szczotka-Flynn L, B arr JT, A nderson RJ, Slaughter ME, Lass JH, et al. A new method for grading the severity of keratoconus: The keratoconus severity score (K SS). Cornea 2006;25(7):794-800. 
38. Alio J L, Pinero DP, A leson A, Teus M A, B arraquer RI, M urta J, et al. Keratoconus-integrated characterization considering anterior corneal aberrations, internal astigmatism, and corneal biomechanics. J Cataract R efract Surg 2011;37(3):552-68.

39. Ishii R, Kamiya K, Igarashi A, Shimizu K, Utsumi $Y$, K umanomido $T$. Correlation of corneal elevation with severity of keratoconus by means of anterior and posterior topographic analysis. Cornea $2012 \mathrm{M}$ ar;31(3):253-58.

40. Torquetti L, Ferrara G, Ferrara P. C orrelation of anterior segment parameters in keratoconus patients. Int J Kerat Ect Cor Dis 2012;1(2):87-91.

41. Gatinel D, Saad A. The challenges of the detection of subclinical keratoconus at its earliest stage. Int J Keratoco Ectatic Corneal Dis 2012;1(1):36-43.

\section{ABOUT THE AUTHORS}

\section{Bernardo T Lopes}

Research A ssociate, Department of O phthalmology, Rio de Janeiro Corneal Tomography and Biomechanics Study Group, RJ , Brazil

\section{Isaac C Ramos}

Research A ssociate, Department of O phthalmology, Rio de J aneiro Corneal Tomography and Biomechanics Study Group, RJ , B razil

\section{Fernando Faria-Correia}

Research Associate, Department of Ophthalmology, University of Porto, Porto, Portugal

\section{Allan Luz}

Research Associate, Department of Ophthalmology, Rio de Janeiro Corneal Tomography and Biomechanics Study Group, RJ, B razil

\section{Bruno de Freitas Valbon}

Research Associate, Department of Ophthalmology, Rio de Janeiro Corneal Tomography and Biomechanics Study Group, RJ, B razil

\section{Michael Wellington Belin}

Professor, Department of Ophthalmology and $V$ ision Science University of A rizona, Tucson, AZ, USA

\section{Renato Ambrósio Jr}

Professor, Clinical Director, Department of Ophthalmology, Rio de Janeiro Corneal Tomography and Biomechanics Study Group, RJ Brazil, e-mail: renatoambrosiojr@terra.com.br

CorrespondenceAddres Rua Conde de B onfim 211/712, Tijuca, Rio de Janeiro, RJ 20520-050, B razil, e-mail: renatoambrosiojr@ terra.com.br 